\title{
É Possível a Fenomenologia de Husserl como Método de Pesquisa em Psicologia?
}

\author{
Ana Maria Lopez Calvo de Feijoo \\ Universidade do Estado do Rio de Janeiro \\ Tommy Akira Goto ${ }^{1}$ \\ Universidade Federal de Uberlândia
}

\begin{abstract}
RESUMO - Neste artigo, pretendemos questionar a possibilidade da utilização do método fenomenológico de Edmund Husserl nas pesquisas em psicologia. Apresentaremos, primeiramente, o projeto de fenomenologia de Husserl, com suas análises sobre a intencionalidade, o método fenomenológico e a redução do empírico ao fenomenológico. De posse dessas concepções, discutiremos a pretensão de Amedeo Giorgi de utilizar o método empírico fenomenológico nas suas investigações em psicologia. Deter-nos-emos, especialmente, no modo como Amedeo Giorgi aplica o método fenomenológico às pesquisas em psicologia para mostrar os momentos imprescindíveis, mas, ao mesmo tempo, ambíguos, da investigação fenomenológica na psicologia. Por fim, levantaremos questões e apontaremos respostas acerca da possibilidade de aplicação do método de Husserl às investigações em psicologia.
\end{abstract}

Palavras-chave: fenomenologia, psicologia fenomenológica, metodologia

\section{Can Husserl's Phenomenological Method Be Used in Psychological Research?}

\begin{abstract}
This article aimed to discuss the possibility of making use of Husserl's phenomenological method in psychology research. Initially, we will present Husserl's phenomenology project taking into consideration his analysis related to intentionality, the phenomenological method and the reduction of the empirical to the phenomenological. Considering these conceptions, we will discuss the pretensions of Amedeo Giorgi in using the phenomenological empirical method in their psychological research. We will take a closer look on how Amedeo Giorgi applies the phenomenological method in psychological research in order to show its essential but also ambiguous moments. Finally, we will raise questions and suggest answers regarding the possibility of applying Husserl's method in psychological research.
\end{abstract}

Keywords: phenomenology, phenomenological phycology, methodology

Este artigo tem como tarefa primordial questionar o modo como o método fenomenológico desenvolvido por Edmund Husserl (1859-1938) vem sendo empregado nas pesquisas em psicologia. Essa ciência tem buscado, desde seu início, a fenomenologia como método de investigação, principalmente quando assume a perspectiva de que o fenômeno psíquico se constitui a partir da intencionalidade - como uma condição inerente à própria vida psíquica para além dela mesma - e, como tal, só pode ser alcançado enquanto vivência que se dá na imanência da consciência. E é esse o espaço decisivo em que as coisas (Sachen) se dão: é aqui que se tem a oportunidade de se confrontar com o efetivamente real. Para Husserl (1913/2006), no entanto, o real tal como tomado pela experiência empírica não pode ser assumido, a princípio, como fundamento, no interior de uma pesquisa científica, verdadeiramente evidente e rigorosa, uma vez que nunca pode se mostrar como completamente apodítico. Assim, Husserl nos mostra que a fenomenologia não é uma ciência de realidades, tal como a psicologia cientifica, mas uma ciência que trata dos fenômenos irreais, eidético e não com o efetivamente real, mesmo este estando aí e sendo também aquilo o que constitui o fenômeno.

1 Endereço para correspondência: Instituto de Psicologia, IPUFU, Campus Umuarama, Bloco 2C, Sala 45, Av. Pará, 1720, Bairro Umuarama, Uberlândia, MG, Brasil. CEP. 38.400-902. E-mail: tommy@ufu.br
Muitas vezes, tal como na Sexta investigação das Investigações Lógicas, Husserl (1901/2007a) referiu-se ao empírico como se o que estivesse em jogo para ele fosse acolher as coisas mesmas em sua dimensão empírica. No desenvolvimento dessa ideia, porém, ele deixa claro que se refere especificamente não ao elemento empírico (real, fatos) propriamente dito, mas à estruturação do empírico, destacando que o modo como o empírico se estrutura é sempre fenomenológico. Isso pode ser entendido nas Ideias para uma fenomenologia pura e para uma filosofia fenomenológica (1913/2006), quando Husserl evidencia que a fenomenologia pura ou transcendental é uma ciência de essências, ou seja, uma ciência eidética e não como ciências de fatos. Por fim, é celebre a afirmação de Husserl (1954/2012) exposta na $\S 2$ da Crise das ciências europeias e a fenomenologia transcendental - obra que constitui os últimos escritos de Husserl -, que diz: "Meras ciências de fatos fazem meros homens de fatos" (Husserl, 2012, p.03).

Disso, tem-se aqui de início o problema de como um método filosófico-fenomenológico pode ser utilizado por uma ciência empírico-natural ou, mais amplamente, tem-se aqui exposto o problema da fundamentação das ciências a partir da Filosofia. Para Husserl (1913/2006), há diferença ontológico-epistemológico entre a filosofia-fenomenológica e as "ciências de fatos" (naturais e humanas), porque, enquanto as "ciências de fatos" lidam com a realidade, ou seja, com coisas e sujeitos efetivo-reais em um mundo espaço-temporal, 
a fenomenologia se constituirá como "ciências de essências" (eidéticas), ou seja, como uma ciência que pretende se fixar exclusivamente no conhecimento de essência.

Dessa consideração inicial, podemos demarcar questões epistemológicas e ontológicas dessa relação, porém a questão a ser destacada aqui é a fenomenologia, ou melhor, como o método fenomenológico de investigação do fenômeno pode ser transportado para as pesquisas em psicologia tal como vem acontecendo? Para alcançar essa questão mais geral, primeiramente teremos que esclarecer a denominação empírico-fenomenológica que vem sendo utilizada por alguns dos estudiosos do método (Castro \& Gomes, 2011; Giorgi, 2006; Giorgi, 2009). Em seguida, elucidar o quanto essa concepção se encontra ou não afinada com a proposta de fenomenologia e de uma psicologia fenomenológica. Sabemos que Husserl se refere às investigações empíricas como pautadas em um método - método científico - que pressupõe as coisas (Dinge) como físico-materiais, dotadas de sentidos objetivos e determinações (espaço-tempo) dadas nelas mesmas. Dessa concepção, Husserl procura evidenciar a impossibilidade de se levar às últimas consequências esse método de maneira apodítica e fundamental. Portanto, parece que se quisermos uma compreensão fenomenológica propriamente dita, o empírico a que se referem investigadores em psicologia (Giorgi, 2006; Giorgi, 2009; Giorgi \& Sousa, 2010; Andrade \& Holanda, 2010; Castro \& Gomes, 2011; Branco, 2014) deve ser fenomenologicamente reduzido. Para Husserl (1927/1990) isso significa sair do âmbito exclusivamente empírico (real, factual) e chegar ao transcendental (irreal, eidético), ou melhor, sair do âmbito do psíquico-empírico para o psíquico-transcendental. Por isso, Husserl (1913/2006) afirma que a "fenomenologia não deve ser uma doutrina das essências de fenômenos reais, mas de fenômenos transcendentalmente reduzidos" (p. 28).

Igualmente, utilizar o método fenomenológico, a fim de adequá-lo às pesquisas psicológicas, ou seja, mantêlo no âmbito empírico, não colocaria em risco o rigor inaugurado e tão pretendido por Husserl? Ou não estaria modificando em essência a proposta da fenomenologia? As diferenciações podem ser de ordem meramente técnica, como defendem os pesquisadores Castro e Gomes (2011) na psicologia? Desse modo, contudo, eles não estariam confundindo ou mesmo modificando a ordem estrutural, metodológica e epistemológica da investigação fenomenológica? Sem dúvida, em todos os procedimentos de investigação fenomenológica na psicologia, o objetivo continua sendo a compreensão do significado do vivido, alcançado mediante uma descrição analítica, apoiada em uma relação de cooperação entre os sujeitos da pesquisa e o pesquisador. Isso, porém, seria o que Husserl concebeu para uma investigação propriamente fenomenológica ou de uma psicologia fenomenológica? Cabe ressaltar aqui que Husserl (1925/2001; 1927/1990) elaborou não só a fenomenologia, mas também uma psicologia fenomenológica, isto é, uma disciplina que visa o esclarecimento da natureza da vida psíquica, das estruturas vividas concretamente e da totalidade dos modos de consciência psíquica. A partir das considerações acima expostas, como deve proceder, então, o estudioso da psicologia na investigação de seus fenômenos? Dado o total abandono de Husserl a toda e qualquer consideração acerca do caráter empírico dos fenômenos, por não tratar dos objetivos da fenomenologia, como então investigar os fenômenos psíquicos, já que este é um traço tão marcante nas pesquisas psicológicas? Para começar a esclarecer as questões propostas, começaremos a discorrer sobre a intencionalidade tal como elaborada por Husserl.

\section{A Noção de Psíquico como Intencionalidade em Husserl}

Primeiramente, importa esclarecer aquilo mesmo que Husserl considera como constitutivo ou essencial do psíquico. Em A filosofia como ciência de rigor (Husserl, 1910/2007b), ele tece considerações acerca do fato de os estudiosos da psicologia de sua época terem desconsiderado, completamente, a natureza mesma dos fenômenos psíquicos. Em um primeiro momento, segundo ele, os estudiosos da psicologia consideravam, incessantemente, apenas o conceito de alma e seus afetos. Depois, diante dos desdobramentos do pensamento moderno, eles passaram a considerar o conceito de subjetividade e representação de maneira psicológico-natural. Husserl, por sua vez, procura evidenciar a necessidade de a psicologia se voltar para o caráter intencional dos fenômenos psíquicos.

Embora, nesse texto, Husserl não esclareça, totalmente, o que tem em vista com a noção de intencionalidade, ele se refere aí claramente às relações imanentes da subjetividade ou da consciência pura, ou seja, fenomenologicamente reduzidas, diferenciando-as, assim, dos fenômenos materiais em jogo em uma consciência empírica, na qual se pressupõe que ela é constituída por propriedades e por uma essencialidade específica (Feijoo, 2011). No entanto, nesse mesmo texto, Husserl (1910/2007b) afirma entre outras coisas que:

É de esperar de antemão que a fenomenologia e a psicologia devem estar próximas uma da outra, referindo-se ambas à consciência, embora de modos diversos e em 'orientação' diversa, podendo dizer-se que à psicologia interessa a 'consciência empírica', (...) algo existente na continuidade da natureza, ao passo que à fenomenologia interessa a 'consciência pura'. (p.19) É nas Investigações lógicas (Husserl, 1901/2007a) e, depois, nas Ideias I (Husserl, 1913/2006), obra fundamental para a compreensão do método fenomenológico, que Husserl vai tematizar a intencionalidade a partir da superação das vertentes tradicionais e modernas, com seus pressupostos de que o psiquismo teria sentidos e determinações dadas. Aqui encontramos a transformação radical que a fenomenologia deve produzir na investigação em psicologia. A análise fenomenológica não só vai permitir transformar completamente o sentido da noção de fenômeno psíquico, como também vai modificar a postura que o investigador dos fenômenos psíquicos irá tomar frente a este fenômeno. Para Husserl (1901/2007a), a psicologia, de modo geral, em seu posicionamento empírico, desconsidera o caráter originário e essencial do psiquismo, uma vez que ela parte de uma predicação naturalista do homem, já definindo o saber, antes de qualquer investigação, daquilo que o homem é, ou seja, o fato de ele ser dotado de psiquismo. Para a fenomenologia de Husserl (1913/2006), a consciência é também transcendental, ou seja, nunca se retém apenas em si mesma, mas se vê 
projetada por seus próprios atos para o campo dos objetos correlatos. $\mathrm{Na}$ medida em que a consciência se realiza por meio de seus atos, ela sempre transcende o campo de realização desses atos. E é nessa linha que Husserl vai proceder a sua investigação da consciência intencional.

É importante destacar que Husserl manteve a ideia geral de intencionalidade de seu amigo e mestre, o filósofo Franz Brentano (1838-1917), e a considerou como um grande avanço filosófico desde Descartes. Contudo, diferentemente de Brentano, Husserl revisitou esse conceito, identificando que a consciência intencional, em verdade, não é única e exclusivamente psicológica, mas que é constituída por uma multiplicidade de atos intencionais, ou seja, que cada modo de consciência tem seus objetos (fenômenos) e vice-versa, indo para além da atribuição psicologista de Brentano (Goto, 2007). Ainda, ao fundar a fenomenologia, Husserl (1901/2007a) descreveu a consciência em vários sentidos, indo além do significado psicologista-empírico dado na época. Em primeiro lugar, a consciência é descrita como unidade de vivências (fluxo de vivências); depois passa a ser tomada como percepção interna das vivências (o ser-consciente) e, por fim, é posicionada como vivência intencional. Claro que, com essa análise, Husserl não descarta e nem desconsidera a existência real da consciência psicológica (empírica), porém evidencia que essa consciência é constituída, também, pela sua condição de ser, ou seja, pela sua condição transcendental.

\section{Considerações acerca do Empírico na Fenomenologia}

Já que, para Husserl, a consciência nunca é só empírica e nem pode ser acessada única e exclusivamente de modo empírico, interessa-nos esclarecer as afirmativas de autores acerca do empírico na fenomenologia e psicologia. Comecemos por Giorgi e Souza (2010), que nos diz:

A teoria da intencionalidade, não negando a dimensão empírica, torna-se independente de uma visão exclusivamente fática dos objetos da consciência, tornando possível o estudo desta, não apenas numa perspectiva naturalista. Por esta razão, Husserl viria a eleger o eidos, a essência, como um objeto de estudo válido, não dependente da matéria de facto, não determinado por contingências factuais, portanto escapando aos métodos de mensuração experimentais. (pp. 44-45)

Assim, mesmo Giorgi e Sousa (2010) tendo clareza da orientação fenomenológica de investigação, Gomes e Castro (2011) alertam para a necessidade de analisar os modelos de transposição metodológica da filosofia para a psicologia, como aconteceu com os modelos empírico-fenomenológico, fenomenológico experimental e neurofenomenológico. Os autores afirmam que: "Os três modelos vislumbrados da transposição da lógica transcendental husserliana para a prática empírico-científica não aparentam ter alcançado, ou mesmo almejado uma reforma epistêmica sólida" (p. 239). Essa afirmação nos parece evidente uma vez que esses três modelos acabam de uma maneira ou de outra naturalizando a "lógica transcendental" e eidética husserliana, uma vez que a ciência psicológica moderna se alicerça em uma visão naturalista.

Ainda, retomando a compreensão de Giorgi (2006) com relação ao rigor necessário para a utilização do método fenomenológico, que, inclusive, não pode prescindir de um estudo aprofundado da fenomenologia de Husserl, a questão que insistentemente não nos permite calar é: de que modo podemos aliar a fenomenologia ao empirismo psicológico (ciência psicológica)? Não seria muito fácil nesse posicionamento recair em uma distorção da proposta de saída da postura empírica frente à investigação da consciência rumo à postura fenomenológica? É importante lembrar que nas Ideias I, Husserl (1913/2006) ao analisar as ciências de fatos e as ciências eidéticas, dedica um capítulo inteiro para explanar sobre "os mal-entendidos naturalistas" e adverte que "o empirismo nega 'as ideias', as 'essências', os 'conhecimentos de essência" e que a ciência "tem de lidar apenas com o que é efetivamente real, passível de experimentação" (p.60). Parece-nos que Giorgi (2009) e Giorgi \& Sousa (2010) ao conceberem uma investigação fenomenológica na psicologia, tentam solucionar o problema do elemento empírico por meio da denominada redução fenomenológica - psicológica. Segundo Husserl (citado por Giorgi \& Souza, 2010):

Por conseguinte, para atingir o objeto de estudo puro e efetivo da psicologia descritiva, exige-se um método que seja praticado total e conscientemente, o qual designa por redução fenomenológico-psicológica - entendida neste contexto para a psicologia. (p.53)

Logo, essa redução é concebida pelo próprio Husserl (1954/2012) como sendo propícia para as investigações em ciências do espírito (humanas), especificamente, para a psicologia, desde que desconsideremos o passo metodológico subsequente, ou seja, da redução transcendental. Ainda, Giorgi afirma (2010) que essa redução consiste no fato de que: “Os atos devem ser entendidos tal como vividos pelos sujeitos. No entanto, não é feita a alegação, por parte do investigador, de que os objetos e as situações vivenciados pelos sujeitos existem na realidade como estes os vivenciaram" (p. 53). Cabe, então, discutirmos agora o que Husserl designa como redução fenomenológico-psicológica. E, então, ver se é possível essa redução viabilizar a reinserção do elemento empírico nas investigações dos fenômenos psíquicos, tal como preconizam os autores. Husserl (1901/2007a), ao se referir à psicologia nas Investigações Lógicas denomina-a de descritiva. Ele nos diz expressamente que a fenomenologia é uma psicologia, porque trata das vivências e toda e qualquer vivência depende da vida psíquica. No entanto, na segunda edição das Investigações lógicas (2007a) e na obra Ideias I (1913/2006), Husserl explicita sua correção conceitual afirmando agora que a fenomenologia não é uma psicologia, porque a fenomenologia se constitui como uma ciência das essências e não ciência dos fatos. Na sua acepção (1952/2000) a "ciência empírica investiga a existência; a eidética, a essência, a mesma essência que integra o conteúdo do existente e o possível existente em geral" (p. 55).

A noção de redução fenomenológica, que se refere à saída do empírico para o eidético-transcendental/fenomenológico, é discutida por Husserl inicialmente nas Investigações lógicas (1901/2007a) e em Ideia da Fenomenologia (1907/1990). E é dessa redução que trata a fenomenologia como método de investigação e pesquisa. Mais tarde, nas Ideias I(1913/2006), Husserl vai passar a não falar somente em redução, mas antes em suspensão. A suspensão, por sua vez, aponta para o total e radical abandono de todos os pressupostos 
ditos hipostasiantes, passando para o acompanhamento da experiência intencional dos objetos que se abre a partir daí. E assim que se alcança, para Husserl, algo além da orientação natural, ou seja, para além de qualquer juízo sobre existência espaço-temporal, seja a consciência, o ego, e a condição de possibilidade de toda e qualquer vida fenomenológica constituinte, inclusive a psíquica. Assim, percebemos que a tentativa de fundamentar a fenomenologia na estrutura denominada eidético-transcendental dos atos intencionais inviabiliza, porém, por completo a prática direta da fenomenologia na psicologia.

O projeto husserliano, em sua fase tardia, nos textos reunidos na obra denominada $A$ crise das ciências europeias e a fenomenologia transcendental, ao menos até a inserção da noção de mundo da vida, parece não interessar à psicologia científica, pois o que interessa a essa área de estudo é a performance da intencionalidade no seu aspecto empírico e o acontecimento das vivências. Essa fase, porém tem plena importância para a psicologia, pois nela Husserl apresenta sua versão sintética daquilo que denominou de "psicologia fenomenológica" e seu "método da redução fenomenológicopsicológico", uma disciplina distinta da fenomenologia. Essa distinção pode ser vista, anteriormente já na introdução do texto da Enciclopédia Britânica, publicado em 1927:

Ao mesmo tempo em que a fenomenologia filosófica, mas sem se distinguir a princípio dela, surgiu uma nova disciplina psicológica paralela a ela, quanto ao método e ao conteúdo: a psicologia apriorística pura ou "psicologia/fenomenológica", na qual, com um afã reformador, pretende ser o fundamento metódico sobre a qual pode, por princípio, erguer-se uma psicologia empírica cientificamente rigorosa. (Husserl, 1927/1990, p.59)

Retomando o $§ 69$ da citada obra Crise, Husserl (1954/2012) além de explanar sobre o a redução fenomenológico-psicológico, afirma que cabe ao psicólogo, em sua pesquisa, não tomar nenhuma posição, nem aceitar, nem recusar, quanto às validades das pessoas por ele investigadas. Por fim deixa-nos claro que: "não existe uma psicologia pura [fenomenológica] como ciência positiva, [...]. Só existe uma psicologia transcendental, que é idêntica à filosofia transcendental" (p.208).

Esclareceremos, ainda, duas noções decisivas para pensar o método fenomenológico: consciência e vivência. Para a fenomenologia husserliana, a consciência não tem conteúdos autonomamente dados, com os quais a consciência poderia se deparar ou não de maneira fática. Objetos não subsistem nem externamente de modo independente, nem internamente como um construto da subjetividade. Ao contrário, a consciência se faz, nesse caso, em sintonia direta com um espaço correlato de imanência-transcendência no qual surge a relação entre consciência intencional e objeto correlato. Husserl utilizou-se do método fenomenológico para investigar o fenômeno da consciência empírica para o transcendental. Para tanto, ele suspendeu de início todas as teorias acerca da consciência, seja essa teoria empírica ou logicamente fundada, suprimindo todas as perspectivas psicologistas e historicistas naturalizantes e assumindo uma postura antinatural frente ao fenômeno mesmo, ou seja, a consciência. Assim, ele alcançou a intencionalidade e buscou acompanhar descritivamente a própria constituição da consciência em ato. Nas Investigações Lógicas (1901/2007a),
Husserl evidenciou a essência da intencionalidade como espaço de dação dos objetos - fenômenos. No entanto, ao prescindir da ideia de uma substancialidade subjetiva subjacente aos atos, ele alcançou o fenômeno pelo exercício do pensamento.

Castro e Gomes (2011) referem-se às criticas que são endereçadas às pesquisas fenomenológicas pelos riscos de vieses que o pesquisador pode cometer ao trabalhar com os dados empíricos, claro que mantendo a preocupação de um ideal científico. A questão que se impõe, então, consiste em assumir uma postura cautelosa quando a investigação fenomenológica se dá a partir dos sujeitos tal como acontece nas pesquisas psicológicas. O que nos parece é que as experiências desses sujeitos tomadas como empíricas e mesmo nos experimentos fazem que a investigação se mantenha em um âmbito de uma pesquisa não fenomenológica, naturalizante, coisificante. Cabe, então, trazer à baila a concepção de vivência tal como discutida pelo filósofo. Perguntemos: o que significa, para Husserl, uma vivência? A vivência consiste na efetivação de uma relação imanente da consciência com o seu campo de objetos. Nas análises de Husserl (1913/2006), portanto, a vivência acontece como uma estrutura irreal, que jamais poderá ser encontrada na realidade enquanto que, para a psicologia, de um modo geral, as vivências são ocorrências reais que não podem ser encontradas senão empiricamente. Husserl coloca fora de ação o objeto real e efetivo e diz que o que aparece é sempre o fenômeno, portanto, sem materialidade, não empírico. Insiste Husserl sobre a orientação fenomenológica do vivido:

A árvore pura e simples pode pegar fogo, pode ser dissolvida em seus elementos químicos, etc. Mas o sentido - o sentido desta percepção, que é algo necessariamente inerente à essência dela - não pode pegar fogo, não possui elementos químicos, nem forças, nem qualidades reais. Tudo o que é peculiar ao vivido, de maneira puramente imanente e reduzido, [...], e que na orientação eidética passa eo ipso para o eidos, está separado de toda natureza e de toda física, não menos que de toda psicologia, [...] por ser naturalista [...]. (Husserl, 1913/2006, p. 206)

Ainda, sobre isso é importante ressaltar que a suposição acerca do empírico, presente no pensamento de Husserl, ocorre pela interpretação equivocada da discussão acerca da intuição sensível e categorial, presente na Sexta investigação (1901/2007a). A intuição sensível, que pressupõe sensibilidade, leva ao erro de se acreditar que o autor se referiria só a certa base material. No entanto, Husserl deixa claro ainda na Sexta investigação que a estruturação do empírico na vivência é sempre fenomenológica. E como a estruturação do empírico na vivência é fenomenológica, por mais que se possa pensar que há o empírico em Husserl, o que efetivamente é acessado não é o empiricamente dado, mas sim a vivência fenomenológica daquilo que se dá. Em conclusão, aquilo que o fenomenólogo atinge naquilo que investiga é sempre algo que se dá no campo de imanência de sua consciência, nas suas vivências, já que tudo que ele acessa é fenomenológico. Após a apresentação dos argumentos de Husserl acerca do porquê e em que a fenomenologia se difere de um saber empírico, podemos concluir que, para esse filósofo, não há como falar de maneira apodítica do plano empírico como se esse fosse o plano 
verdadeiro e originário. Para Husserl, é o que se experimenta fenomenologicamente que se mostra como o mais próximo e evidente. Dito de maneira ainda mais expressa, a constituição do evidente, daquilo que se vive, nunca é aqui empírico, mas é essencialmente fenomenológico. O empírico precisa ser fenomenologicamente reduzido, para que ele alcance a sua evidência propriamente dita. O campo do fenômeno, por sua vez, não é o campo das razões objetivas, mas as razões nascem efetivamente da coisa tal como se apresenta no campo de imanência da consciência.

$\mathrm{O}$ que se têm então entre os principais investigadores que utilizam o método fenomenológico ou a teoria fenomenológica na psicologia, nos diversos sentidos que vai do empírico ao experimental (Andrade \& Holanda, 2010; Giorgi, 2008; Giorgi, 2009; Giorgi \& Sousa, 2010; Janzen, Castro, \& Gomes, 2013) é a modificação de um ou outro elemento (consciência, vivência, descrição fenomenológica, redução psicológica), considerado imprescindível na fenomenologia husserliana, estabelecendo divergências e convergências com relação ao método fenomenológico. Para esses pesquisadores, essas aproximações são apenas de ordem técnica e compreensiva e, portanto, não abalariam a ordem estrutural do fenômeno. Para ampliar essas considerações, vamos então analisar a proposta de pesquisa qualitativa em psicologia do Amedeo Giorgi (2006), principal elaborador das pesquisas empírico-fenomenológicas, para assim, podermos nos posicionar sobre tal proposta.

\section{Elementos Imprescindíveis ao Método Fenomenológico de Investigação Psicológica}

Há ainda outros modos de aproximação com o método inaugurado por Husserl, afirmam alguns estudiosos do método (Andrade \& Holanda, 2010; Branco, 2014; Castro \& Gomes, 2011; Giorgi, 2009; Goto, 2007; Spiegelberg, 1982; Strasser, 2010). Alguns fenomenólogos tais como Edith Stein, Martin Heidegger, J.P. Sartre, M. Merleau-Ponty referem-se a muitas e variadas fenomenologias e, por isso, poderiam desconsiderar um ou outro aspecto do método tal como foi originalmente projetado por Husserl. Na psicologia, Castro (2013) afirma que tradicionalmente têm-se utilizado na pesquisa empírica a ferramenta fenomenológica de duas maneiras: como recurso qualitativo-descrito (Giorgi, 2009) e como um retorno ao projeto husserliano de refundação das ciências humanas (Goto, 2007). Ainda, o autor apresenta e defende uma terceira via, ou seja, como "um aporte menos diretivo e mais comparativo entre entendimentos do valor empírico das experiências [...] além da flexibilização de regras metodológicas na condução da pesquisa empírica" (Castro, 2013, p. 213).

No entanto, essas estratégias não abalariam os fundamentos essenciais presentes no projeto husserliano? Sim, abalariam, mas o que se quer aqui é evidenciar o quão fenomenológico é a pesquisa fenomenológica de caráter husserliano, defendido como método de pesquisa na psicologia. A fim de tratar as questões anteriormente levantadas, vamos discorrer acerca das considerações de Giorgi (2009) acerca das diferentes utilizações e adaptações do método inaugurado por Husserl. Giorgi (2006) aponta para o crescente interesse dos cientistas sociais pela utilização do método fenomenológico de investigação. No entanto, alerta para o perigo da utilização imprópria do método. Ao se deparar com pesquisas denominadas fenomenológicas e realizadas pela psicologia e enfermagem, por exemplo, ele encontrou problemas que incompatibilizavam o que fora feito com alguns dos pressupostos fenomenológicos tais como elaborados por Husserl. Assim, Giorgi conclui que uma exigência básica para a utilização do método fenomenológico nas pesquisas psicológicas e sociais deve ser a de partir de um estudo prévio e rigoroso da filosofia fenomenológica.

Giorgi (2006) ressalta também que a fenomenologia de Husserl consiste em um método interrogativo do fenômeno que jamais se reduz aos fatos. Nesse empreendimento, o estudioso destaca pelo menos três procedimentos metodológicos que são imprescindíveis na psicologia e demais ciências humanas. O primeiro é adotar uma atitude fenomenológica, que consiste em uma suspensão (epoché) de todo e qualquer posicionamento ontológico-epistemológico frente ao que pretendemos investigar. Depois, trata-se de encontrar a instância do fenômeno que nos interessa estudar. Em um terceiro momento, utilizar o exercício da variação livre da imaginação para poder reconduzir o fenômeno ao campo intencional onde ele se faz fenômeno e, assim, alcançar a sua essência, considerada como sentido/significação. Por fim, descrever a essência do fenômeno que se alcançou por meio a todo esse processo. Ainda, Giorgi (2006) alerta que algumas variações do método são legítimas e outras não. Ele considera legítimas as que são fieis à filosofia e aos princípios fenomenológicos em suas práticas de pesquisa. Segundo Giorgi, estas são algumas das variantes encontradas no método fenomenológico de pesquisa que devem ser repensadas: a interpretação na redução fenomenológica, o papel da variação imaginativa, a questão da generalização e a verificação dos dados.

Em seguida, Giorgi e Sousa (2010) esclarecem, detalhadamente, as exigências e procedimentos metodológicos imprescindíveis à utilização do método fenomenológico de Husserl nas investigações psicológicas e afirmam que a investigação fenomenológica consiste, em primeiro lugar, basicamente na redução psicológico-fenomenológica, na qual ocorre, com esforço, a saída do empírico para o fenomenológico. É isso que Husserl denomina de atitude antinatural (Husserl, 1901/2007). Giorgi e Sousa (2010) enfatizam que, com relação à redução fenomenológica, fazse necessário que o pesquisador coloque em suspenso todo o conhecimento teórico, assim como sua própria experiência passada, uma vez que essa experiência determina de maneira decisiva o modo como ele se posta em relação aos fenômenos, aos outros seres e a si mesmo. Toda a atenção do pesquisador deve estar focada no fenômeno tal como este se dá à consciência, de tal modo que ele supere a posição inicial que o leva a tomar o que é visado como sendo empírico.

Essa redução acontece no momento em que tudo passa a se dar, a se mostrar fenomenologicamente. Portanto, agrupar diferentes experiências anteriores em um rol idêntico do que se mostra na experiência atual pode conduzir a um erro e a um desvio (Giorgi, 2006). Para Husserl (citado por Giorgi, 2006), a análise da experiência atual deve ser cuidadosamente analisada antes de ser relacionada a qualquer 
experiência anterior. O problema aqui é que, ao escolher os sujeitos a serem pesquisados, existem no pesquisador considerações prévias e naturais de tal fenômeno a ser estudado e recortado. Ao se investigar, por exemplo, o "ajustamento materno e paterno em experiências vivenciadas pelos pais no pós-parto", apresentado por Giorgi e Sousa (2010), a pesquisadora em questão apresenta o fenômeno "materno", "paterno", "desenvolvimento", entre outros, compreendidos a partir da ciência psicológica. Ela aceita de antemão considerações acerca do desenvolvimento humano, maternidade, paternidade, gravidez entre outros, preconizadas pela psicologia. Em nenhum momento executa ou anuncia a necessidade de radicalizar a investigação na orientação fenomenológica de fenômenos fundantes (materno, paterno, desenvolvimento humano, ser humano) antes da análise dos fenômenos fundados (ajustamento materno e paterno no pósparto). Destacamos Stein (1994/2003) que, sobre o método fenomenológico, diz que:

Não consiste em questionar as teorias sobre as coisas, ao contrario, é deixar de lado o quanto for possível o que ouvimos e lemos, ou que nós mesmos produzimos, a fim de se achar a melhor solução para a situação. Isso para, por assim dizer, acercarmo-nos das coisas com um olhar livre de preconceitos e absorvermo-nos da intuição imediata. (p. 33)

Portanto, aquilo que se deve alcançar pela redução fenomenológica jamais se presta a aceitar previamente uma interpretação teorizante ou objetificante qualquer.

Em segundo lugar, a pesquisa fenomenológica deve afirmar o lugar da variação imaginativa, encontrando a instância do fenômeno que interessa estudar. E, usando o processo de variação livre da imaginação, alcançar a determinação da essência do fenômeno. Tudo isso, porém, só se conquista em um plano não empírico, no plano das variações eidéticas. Ainda, cabe lembrar que a imaginação também se dá na imanência da consciência, ou seja, que o objeto imaginado não existe fora ou mesmo dentro da mente como algo dado. Nesse contexto, o ato de imaginar tem um papel decisivo para que se determinem as facetas possíveis. Ao perceber algo, a parte que está atrás necessariamente se vela. A imaginação acompanha as facetas a partir de uma unidade com o ato de perceber e de lembrar. A variação imaginativa é fundamental no método fenomenológico. Se essa etapa não for considerada, a redução fenomenológica não será devidamente exercitada (Giorgi, 2006).

Por fim, a terceira etapa, a generalização, diz respeito à possibilidade de o método fenomenológico fazer generalizações, visto que, para Husserl, em todo geral está o particular e em todo particular encontra-se o geral. Quanto à generalização - essa é uma questão ampla e complexa que não entraremos aqui -, essa pode ser alcançada desde que se empregue a redução eidética, pois aí já se está no âmbito da generalidade. Com a ajuda da variação imaginativa, pode-se alcançar uma intuição eidética e descrever uma descoberta fundamental que é intrinsecamente generalizável (Giorgi, 2006).

Muitas das prescrições de como atuar fenomenologicamente sugerem a verificação dos resultados, algo que pode ser pensado no âmbito daquilo que Husserl (1901/2007a) chama, em suas Investigações lógicas, de concreção de sentido, mas que apresenta aqui problemas adicionais. Essa verificação ocorre quando os participantes entram em contato com os resultados levantados pelo investigador. Giorgi (2006) admite, por sua vez, a falha desse procedimento. Primeiramente, porque os participantes, ao validarem os resultados, assumem uma atitude natural, partindo do ponto de vista cotidiano. Em segundo lugar, o investigador, ao chegar a suas conclusões, o faz a partir da sua intencionalidade, do sentido doado à experiência, logo não passível de comprovação.

Outra questão, além das levantadas por Giorgi (2006), que consideramos importante discutir é a questão disparadora, apresentada por muitos pesquisadores que se utilizam do método fenomenológico. Essa questão é apresentada aos participantes da pesquisa com o objetivo de que, a partir dela, os participantes apresentem uma descrição de sua experiência acerca do tema que se pretende investigar. A problematização que aqui se impõe aponta para a necessidade de saber se a questão disparadora não pode fazer incorrer no risco de, ao perguntar, não ser possível sustentar o pressuposto da redução fenomenológica. Nesse caso, o que fazer para garantir a redução sem a qual se torna impossível investigar fenomenologicamente? A questão disparadora tem validade para o processo de coleta de dados ou mesmo para a entrevista que está estabelecida na orientação natural. Em uma pesquisa fenomenológica o que se deve analisar é a vivência presente na experiência e não uma experiência daquela vivência. A proposta que aqui se anuncia, inspirada na comunicação indireta, tal como utilizada metodologicamente por Kierkegaard (1849/1996), consiste em que a questão disparadora se dê em uma linguagem indireta. Desse modo, não se abordaria diretamente a questão que se quer investigar, deixando que, na conversa e apenas nela, a vivência em questão aparecesse. Assim, evitar-se-ia que, na questão disparadora, aparecesse um recorte empírico com o qual se corre o risco de restringir a aparição do fenômeno em todos os sentidos possíveis da experiência.

Toda essa elaboração metodológica parece-nos, em um primeiro momento, bastante coerente com a fenomenologia e com o método fenomenológico, pois reproduz os procedimentos elaborados por Husserl. No entanto, se a proposta de Giorgi e Sousa (2010) é desenvolver uma investigação psicológica fenomenológica na psicologia, essa deve de imediato sair da experiência empírica (fatos) e ir às vivências psíquicas (eidético). Lembremos que "não existe uma psicologia pura como ciência positiva, uma psicologia que pretenda pesquisar universalmente, como fatos reais, os homens que vivem no mundo, do mesmo modo como as outras ciências positivas da natureza e do espírito" (Husserl, 1954/2012, p. 208). Se for assim, qual o rumo da aplicação dessa proposta? Essa proposta de investigação, se levada a cabo, não passaria a se constituir como uma análise própria da fenomenologia de Husserl e não de uma psicologia? Ainda, será que essa análise não se constitui em uma análise psicológica da fenomenologia? Ou uma análise psicológica estabelecida como fenomenológica? Nesse caso, parecem existir certas ambiguidades e confusões conceituais dos autores na relação da fenomenologia de Husserl com a psicologia, pois, na reflexão fenomenológica, por exemplo, mesmo na psicologia, a redução deve ser levada a cabo, o que significa reconduzir o empírico do fenômeno ao seu fundamento, ou seja, para o âmbito eidético-transcendental. 
Posto dessa maneira, a solução que nos parece mais coerente, principalmente na tentativa de solucionar essas ambiguidades e confusões, não está no desenvolvimento de uma psicologia empírico-fenomenológica como sugere Amedeo Giorgi, mas sim naquilo que o próprio Husserl (1925/2001) sugeriu como a psicologia fenomenológica. Essa sim seria a autêntica ciência eidética que visa a uma investigação do psicológico fundada a partir da fenomenologia de Husserl. Para Husserl, a psicologia fenomenológica, como descreve Goto (2007), constituise como uma psicologia radical (totalmente diferente das psicologias empíricas e experimentais) porque só esta é fenomenológica por estar dirigida genuinamente à vida psíquica em si mesma e a suas estruturas, conduzindo seu olhar verdadeira e genuinamente para a interioridade psíquica. Para isso, essa psicologia fenomenológica, como sintetiza Husserl (1925/2001), resume-se com características básicas, a saber: constitui-se como uma ciência a priori (e não empírica) e eidética (e não ciências de fatos), possuindo um caráter intuitivo e de descrição pura das vivências psíquicas.

A psicologia como uma ciência a priori e eidética significa que a psicologia, em sentido estrito, deve ser uma ciência das universalidades (necessidades essenciais) das vivências psíquicas, ou seja, como uma ciência das essências universais do psiquismo, sem as quais seriam inconcebíveis os seres psicológicos. Nesse ponto, já percebemos de imediato a suspensão do empírico, da realidade espaçotemporal dos vividos psíquicos. Ainda, essa psicologia deve, então, desenvolver-se a partir da descrição da essência (pureza) da estrutura psicológica tal como aparece à intuição (categorial) e à reflexão. Isso significa apreender o essencial da vida anímica. Para Husserl (1925/2001), os psicólogos não são filósofos, porque aqueles buscam a teoria essencial pura do psíquico, a partir do homem natural, do individuo e do social-psíquico, enquanto que estes buscam uma filosofia transcendental, pautada na vida transcendental. Dessa maneira, o psicólogo, como concebe Husserl (1954/2012), que busca uma ciência rigorosa da vida interna e intencional, deve adotar o método da redução fenomenológicopsicológica, que é a redução eidética, porque só assim poderá se desvencilhar da orientação natural-científica, como também da atitude natural na qual vivem todos, inclusive o psicólogo. Husserl diz que:

Ao psicólogo, no meio desta vida, mas na sua atitude de 'observador desinteressado', é tematicamente acessível a cada vida intencional, conforme a vive cada sujeito, ele mesmo e cada comunidade particular de sujeitos, que são tematicamente acessíveis às efetivações dos atos, o agir perceptivo e de qualquer outro modo experienciador, os intuitos cambiantes do ser, da vontade, etc. (Husserl, 1954/2012, p. 194)

A psicologia proposta por Husserl, como insiste Goto (2007), reconduz a uma reformulação radical da psicologia empírica e científica para uma psicologia fenomenológica, e, principalmente, ao esclarecimento evidente dos principais conceitos usados na psicologia, tais como: consciência, percepção, afetividade, imaginação, fantasia, cognição, etc. Tudo isso, a partir desses princípios mesmos, ou seja, a partir da própria identidade e constituição dos referidos processos psicológicos vividos. Contudo, para que isso aconteça não se pode colocar a vida psíquica em uma análise natural científica, por meio de perguntas disparadoras que levam, muitas vezes, às opiniões já pré-estabelecidas. Para que uma análise fenomenológica se dê a termo, deve-se partir das vivencias mesmas e como elas se dão, em nossa vida humana, descrevendo-a como tal e identificando as suas estruturas sintéticas e universais.

Com a discussão aqui desenvolvida, concluímos que a fenomenologia de Husserl, como método de investigação em psicologia, deve ser preservada em todos os seus elementos e momentos fundamentais, sem os quais se tornaria inviável considerar que realmente se utilizou o método de maneira radical. As distinções existentes entre as diferentes modalidades não podem ser de ordem meramente técnica, como defendem alguns pesquisadores, tais como Giorgi (2006) e Giorgi e Sousa (2010), pois, desse modo, correríamos sempre o risco de abalar a ordem estrutural da investigação fenomenológica husserliana, propriamente dita. Para que isso não ocorra, é fundamental que se retome a concepção de psicologia fenomenológica já elaborada e analisada por Husserl para que se garantam os momentos imprescindíveis que uma investigação possa ser, sem sombra de dúvida, fenomenológica.

\section{Considerações Finais}

Considerando a fenomenologia em suas indicações rigorosas, tal como defendidas por Husserl (1910/2007b), uma investigação psicológica deve constituir-se como psicologia fenomenológica, pautada no método fenomenológico e deve manter, no mínimo, os seguintes momentos, que são, por conseguinte: a redução eidético-fenomenológica, descrição dos vetores internos ao fenômeno psíquicos, a explicitação e a descrição das vivências psíquicas (Feijoo \& Mattar, 2014). Mas a questão que se impõe frente à conclusão dessas autoras é: ao manter esses momentos, a psicologia não se confunde com a própria fenomenologia?

Acompanhemos, pois, o que diz Husserl (1954/2012): ao estabelecer, principalmente, a redução, a psicologia deixa o âmbito empírico para adentrar o transcendental, "A pura psicologia não conhece justamente senão o subjetivo, e admitir aí como existente algo de objetivo é já dela ter aberto mão" (p. 209).

A investigação fenomenológica consiste na redução fenomenológica ou psicológica. A redução deve eliminar todos os posicionamentos ontológicos-naturais. A redução, incessantemente, a todo instante, suspende o comportamento hipostasiante. Suspender as hipostasias significa reduzir aquilo que se mostra e, assim, assumir uma postura antinatural diante do que se apresenta. De acordo com Spiegelberg (1982), nas pesquisas empíricas nem sempre foi resguardado o procedimento da suspensão (epoché), próprio das investigações fenomenológicas. E, referindo-se a Amedeo Giorgi, podemos afirmar que a questão do empírico para o eidético, como vimos, ainda tem sido um dos problemas na elaboração de uma investigação empírico-fenomenológica na psicologia. Ainda, a investigação fenomenológica consiste na descrição dos vetores internos ao fenômeno psíquico. Enfim, investigar fenomenologicamente consiste em partir do próprio fenômeno e acompanhar a rede de significações que 
atravessa o fenômeno. O movimento da Duquesne University com relação às investigações fenomenológicas em psicologia manteve-se fortemente pautado na utilização da variação imaginativa, embora como já dito acima, desconsiderou a suspensão.

Por fim, o terceiro momento consiste na explicitação e descrição das vivências. Ao acompanhar o fenômeno psíquico tal como ele acontece no seu campo de mostração, sem nenhuma determinação aprioristicamente dada, torna-se efetivo aquilo que se dá ali. Importa alcançar o ponto em que as coisas significam o que significam. O investigador, então, descreve o fenômeno a partir dos sentidos que aparecem na própria experiência. Por fim, o pesquisador deve descrever cuidadosamente a essência da descoberta, ou seja, os vetores internos ao fenômeno.

Mesmo considerando esses três momentos, os pesquisadores devem problematizar esses procedimentos nas investigações em psicologia. Como vimos trazem muitas confusões teóricas e questões, ainda, a serem desenvolvidas.

Tal como procuramos explicitar aqui, diferentemente do que fazem Giorgi e Sousa (2010) como psicologia empíricofenomenológica, mesmo denominando-a como psicologia fenomenológica; a psicologia fenomenológica para Husserl (1925/2001) é uma ciência eidética, não natural e nem empírica, assim, deve-se fixar na descrição da essência (pureza) da estrutura psicológica tal como aparece à intuição reflexiva e ir diretamente à vivência e não à experiência e menos ainda ao significado da experiência (hermenêutica, por exemplo). Isso significa querer apreender o essencial da alma.

O psicólogo, como orienta Husserl (1954/2012), tem que erguer uma ciência rigorosa da vida psíquica, da vida intencional e, para isso, deve impor o método da redução fenomenológico-psicológica (redução eidética), porque só assim ele poderá se desvencilhar da orientação naturalcientífica, como também da atitude natural, na qual todos vivem, até mesmo o psicólogo. A redução fenomenológicopsicológica, levada a cabo pela epoché psicológica, possibilitará ao psicólogo a suspensão de sua atitude ingênua e natural, reconduzindo-o ao objeto mais próprio: a vida anímica pura. É nesse sentido que declara Husserl (1954/2012): “Assim, ele [o psicólogo] tem em geral como tema mais próximo e fundamental a pura vida ativa [dos atos intencionais] das pessoas e, logo, em primeiro lugar, a vida da consciência em sentido estrito" (p. 194).

Assumir uma atitude fenomenológica de investigação seja em psicologia ou qualquer outra área de estudo consiste em ter em mente os pressupostos fenomenológicos presentes no projeto husserliano. E a característica básica desse projeto é que nele pensemos a partir da mobilidade estrutural do fenômeno. E, ao assumirmos uma atividade fenomenológica de investigação, a atitude fenomenológica vai consistir em acompanharmos o processo de realização do próprio acontecimento fenomenológico, ou seja, a rede de direcionalidades que atravessa o fenômeno.

Para terminarmos esta exposição, vamos, então, nos pronunciar acerca da principal inspiração deste manuscrito: o método fenomenológico de investigação do fenômeno pode ser transportado para as pesquisas empíricas em psicologia tal como vem acontecendo? Após um breve diálogo com a proposta de Amedeo Giorgi, pesquisador que concebeu uma investigação empírico-fenomenológica, concluímos que essa investigação em psicologia ainda não atingiu seu objetivo final e que seus princípios básicos ou ainda não foram bem compreendidos ou são implantados de forma diferente, apesar de todos os sérios esforços. E é isso que devemos entender, até mesmo, em sua proposta de método para a psicologia. $\mathrm{O}$ próprio Giorgi (2006; 2009) diz que não devemos desistir, mas ficar atentos para que possamos cada vez mais conhecer o método, para com ele proceder com o rigor tão defendido por Husserl.

No conjunto dos argumentos expostos, este estudo procura ir além das considerações de Giorgi (2006), Giorgi (2009) e Giorgi e Sousa (2010), que apontam para o desenvolvimento de uma investigação empírico-fenomenológica na psicologia, mostrando as dificuldades de estabelecer a relação da fenomenologia com a ciência psicológica. Tal dificuldade é encontrada justamente quando na tentativa de ultrapassar definitivamente o empírico para alcançar o eidético (vivência psíquica). Como, também, buscamos ir além das críticas de Andrade e Holanda (2010), Castro e Gomes (2011) e Castro (2013), que apontam de maneira histórica e genérica ao modelo oferecido por Amedeo Giorgi. Aqui pudemos oferecer alguns pontos em destaque do método de Giorgi, mostrando algumas de suas transposições equivocadas, tais como: o problema da redução fenomenológico-psicológica, a questão da experiência e da vivência. Além da própria concepção do que seria uma investigação psicológico-fenomenológica, pois aqui concluímos que os autores acabam modificando aquilo que concebeu Husserl como psicologia fenomenológica, na medida em que não analisam os fenômenos fundantes; portanto, não realizando plenamente a redução. Assim, não alcançam as vivências psíquicas propriamente ditas, mas se estabelecem no sentido/significado das experiências de maneira parcial. Claro que isso não invalida a investigação proposta, apenas conclui-se que não atingem ainda o objetivo de uma psicologia fenomenológica. Assim sendo, o método fenomenológico se estabelece de modo similar aos outros métodos de pesquisa qualitativa em psicologia, tais como: análise de discurso, análise de conteúdo ou hermenêutico (Branco, 2014).

Para resolver essa relação da filosofia fenomenológica com as ciências, a única saída é retomarmos o caminho já indicado e trilhado por Husserl: a psicologia fenomenológica. Para Husserl, a psicologia autenticamente fenomenológica, longe de ser uma psicologia empírico-fenomenológica, fenomenológico-experimental ou mesmo um projeto de refundação, apesar de todos os sérios e honestos esforços; reformularia a psicologia empírica e científica para, assim, constituir-se como psicologia fenomenológica; esclareceria os principais conceitos usados na psicologia; fundar-se-ia como uma ciência universal da subjetividade psíquica; buscaria descrever as vivências intencionais e as suas estruturas sintéticas e universais; e, por fim, constituirse-ia como uma disciplina propedêutica à fenomenologia transcendental (Husserl, 1925/2001; Husserl, 1927/1990; Husserl, 1954/2012).

Husserl já tinha identificado uma série de problemas e, por isso, concebeu a fundação de uma nova psicologia, uma nova teoria do conhecimento, que também se constituía como uma propedêutica à fenomenologia transcendental. Contudo, não 
devemos confundi-la com uma nova abordagem da psicologia e nem com uma metodologia empírica para a psicologia, já que o fenomenólogo sempre se posicionou de maneira crítica à aceitação total do naturalismo e do relativismo das análises psicológicas empíricas e experimentais. Por fim, é possível posicionarmo-nos contra o estabelecimento de um conceito de abordagem na psicologia ou mesmo um procedimento metodológico na investigação psicológica, pelos contrassensos aqui brevemente advertidos, pois, para Husserl, a psicologia funda-se, sem dúvida nenhuma, na constituição de uma ciência eidética e transcendental.

\section{Referências}

Andrade, C., \& Holanda, A. (2010). Apontamentos sobre pesquisa qualitativa e pesquisa empírico-fenomenológica. Estudos de Psicologia (Campinas), 27(2), 259-268.

Branco, P. C. C. (2014). Diálogo entre análise de conteúdo e método fenomenológico empírico: Percursos históricos e metodológicos. Revista da Abordagem Gestáltica, 20(2), 189-197.

Castro, T. G. (2013). Percepção e autoconsciência: Modelos experimentais de naturalização da fenomenologia (Tese de doutorado). Porto Alegre: Universidade Federal do Rio Grande do Sul.

Castro, T. G., \& Gomes W. B. (2011). Movimento fenomenológico: Controvérsias e perspectivas na pesquisa psicológica. Psicologia: Teoria e Pesquisa, 27(2), 233-240.

Feijoo, A. M. (2011). A existência para além do sujeito. Rio de Janeiro: Viaveritá.

Feijoo, A. M., \& Mattar, C. (2014). A fenomenologia como método de investigação nas filosofias da existência e na psicologia. Psicologia: Teoria e Pesquisa, 30(4), 441-447.

Giorgi, A. (2006). Difficulties encountered in the application of the phenomenological method in the social sciences. Análise Psicológica, 3(24), 353-361.

Giorgi, A. (2009). The descriptive phenomenological method in psychology: A modified husserlian approach. Pittsburgh, PA: Duquesne University Press.
Giorgi. A., \& Sousa, D. ( 2010). Método fenomenológico de investigação em psicologia. Lisboa: Fim de século.

Goto, T. A. (2007). Introdução à psicologia fenomenológica - A nova psicologia de Edmund Husserl. São Paulo: Paulus.

Husserl, E. (1990). El artículo de la Encyclopaedia Britanica (Luis Gonzales, Trad.). Mexico: UNAM. ( Original publicado em 1907)

Husserl, E. (2000). Ideias para uma fenomenologia pura e para uma filosofia fenomenológica (Vol. III - La fenomenologia y los fundamentos de las ciencias; L. Gonzales, Trad.). Mexico : UNAM. (Original publicado em 1952)

Husserl, E. (2001). Psychologie phénoménologique (P. Cabestan, N. Depraz \& A. Mazzu, Trad.). Paris: Vrin. ( Original publicado em 1925)

Husserl, E. (2006). Ideias para uma fenomenologia pura e para uma filosofia fenomenológica (Vols. 1 e 2; M. Suzuki, Trad.). São Paulo: Ideias \& Letras. (Original publicado em 1913).

Husserl, E. (2007a). Investigações lógicas (Vols. 1-2; P. Alves \& C. Marujão, Trad.). Lisboa: Centro de Filosofia da Universidade de Lisboa. (Trabalho original publicado em 1901)

Husserl, E. (2007b). La filosofía como ciencia estricta (E. Taberning, Trad.). La Plata: Terramar Ediciones. (Trabalho original publicado em 1910)

Husserl, E. (2012). A Crise das ciências europeias e a fenomenologia transcendental. Uma introdução à filosofia fenomenológica (Diogo Falcão, Trad.). Rio de Janeiro: Editora Forense Universitária. (Original publicado em 1954).

Janzen, M. R., Castro, T. G., \& Gomes, W. B. (2013). Ação corporal $\mathrm{e}$ as reversões entre consciência e movimento: $\mathrm{O}$ realismo fenomenológico. Revista da Abordagem Gestáltica, 19(1), 76-84.

Kierkegaard, S. (1996). Mi punto de vista (J. M. Velloso, Trad.). Madrid: Aguilar. (Original publicado em 1849)

Spiegelberg, H. (1982). The phenomenological movement: A historical introduction ( $3^{\mathrm{a}}$ ed.). Boston: Martinus Nijhoff Publisher.

Stein, E. (2003). La estructura de la persona humana (J. Mardomingo, Trad.). Madrid: B.A.C. (Original publicado em 1994).

Strasser, S. (2010). Fenomenologia e ciências do homem. (T. Alves, Trad.). Pelotas: UFPEL. 